DOI: $10.14451 / 1.203 .147$

\title{
ЭКОНОМИКА ВПЕЧАТЛЕНИЙ КАК НОВЫЙ ТРЕНД
}

\author{
(C) 2021 Мордвинова Татьяна Григорьевна \\ студент \\ Сибирский Федеральный Университет, Институт Управления Бизнес-процессами, Россия, Красноярск \\ E-mail: Tanyacds2000@mail.ru \\ (c) 2021 Соснина Валерия Алексеевна \\ студент \\ Сибирский Федеральный Университет, Институт Управления Бизнес-процессами, Россия, Красноярск \\ E-mail: lera.sosnina.01@mail.ru

\section{(c) 2021 Щеголихина Вероника Ильинична} \\ студент \\ Сибирский Федеральный Университет, Институт Управления Бизнес-процессами, Россия, Красноярск \\ E-mail: verasheg1234@gmail.com
}

Научный руководитель - Жуков М.Ю., ассистент кафедры «Экономика и управление бизнес процессами», ИУБП, Сибирский Федеральный Университет.

В статье рассмотрены сущность экономики впечатлений (опыта), как она повлияла на потребителей, их поведение и мышление, и на различные компании. Рассмотрены различные факторы, которые повлияли на становление данного типа экономики, а также приведены примеры того, где и как сейчас эти факторы используются. Также было рассмотрено то, как ведут себя и справляются с трудностями различные поколения с появлением таких изменений.

Ключевые слова: Впечатления (опыт), поколение, маркетинг, общество, автоматизация

«Экономика опыта» или «экономика впечатлений» - относительно новый термин, описывающий новую модель потребления, за которой, как считают эксперты, стоит будущее.

Более 20 лет прошло с тех пор, как Джозеф Пайн II и Джим Гилмор представили концепцию «Экономики впечатлений», выявившую и описавшую явление, которое было только на начальных этапах и которое росло все больше и больше. Они объяснили, что после аграрной, промышленной и сервисной экономик наступает экономика впечатлений (опыта). Теперь это то, что потребитель требует от брендов и бизнеса. И они были правы, потому что, по мнению консалтинговых фирм, с 2020 года качество обслуживания клиентов стало превосходить цену и продукт в качестве ключевого отличительного признака бренда.

С точки зрения потребления, существует четыре вида впечатления:

Развлечение. Продукт или услуга, которые связаны с позитивными вещами и могут вызывать эмоции в сердцах потребителей. Просмотр рекламных роликов может вызвать положительные эмоции и желание купить товары.
Обучение. Потребители полностью погружены в этот процесс и выполняют различные действия для приобретения знаний и навыков (обучающие программы, развивающие игры и т.д.).

Уход от реальности. Этот человек полностью погружен в процесс и активно в нем участвует. Например: фитнес-центр (их абонемент приобретается не только в практических целях, но и для того, чтобы «получить» эмоции от самого занятия).

Эстетика. Люди погружены в эстетические впечатления, но они все еще являются пассивными. Пример, сходить в кафе за чашечкой кофе (можно выпить его и дома, но в кафе ходят, чтобы насладиться комфортной атмосферой и новыми впечатлениями).

Наиболее распространенные типы впечатлений в России - это развлечения с моделью пассивного поглощения и получения ощущений извне. При пассивном участии потребитель не оказывает непосредственного влияния на представление. Поглощение возникает, когда впечатление переносится во внутренний мир человека и удерживает его внимание. К таким типам относятся классический театр и кино. В последние 
несколько лет стали актуальными позитивные модели - обучение и эскапизм: иммерсивные театры, кулинарные школы, задания и другие интерактивные практики.

Переход от продажи услуг/продуктов к продаже впечатлений сегодня для существующих компаний будет не легче, чем во время последнего великого экономического сдвига, от промышленной экономики к экономике услуг.

Компаниям трудно понять, как справляться с новым сценарием, где все имеет значение, где клиенты играют, как актер, несколько ролей на одной сцене, воспринимая бренд через несколько точек соприкосновения. В настоящее время на потребительские покупки в большей степени влияют впечатления, которые оказывают бренды, а не только сам продукт.

В этом сценарии люди демонстрируют новое экономическое поведение, новый способ принятия решений и пересмотра приоритетов, новый образ мышления, который меняет все, что мы знаем о брендах, маркетинге и коммуникациях.

Владелец малого бизнеса на первом этапе может быть в отчаянии. У крупных брендов больше капитала, чтобы тратить его на впечатления, и это правда. Но крупным брендам сложнее налаживать значимые связи со своими клиентами, потому что предоставление впечатлений - это организационное мышление.

Мир переживает изменения в этой новой экономической модели, в которой многие компании меняются и трансформируются, чтобы адаптироваться к новой динамике потребителей. Это изменение происходит с экспоненциальной скоростью из-за многих ускоряющих факторов, которые способствуют созданию этого нового сценария.

Новое поколение тратит свои деньги больше на желаемые впечатления или события по сравнению с покупкой желаемого продукта. А в США миллениалы стали крупнейшим поколением, тратящим средства на услуги, связанные с впечатлениями (опытом), и за последние несколько лет они выросли почти в четыре раза быстрее, чем расходы на товары.

Бизнес, основанный на опыте, сегодня имеет большое конкурентное преимущество. В обзоре Harvard Business сообщается: «...бренды, ориентированные на то, чтобы покупатели получали впечатления и при покупке, и после, достигают среднего темпа роста выручки в 23\%, тогда как другие опрошенные компании - 13\%».
Существуют факторы, которые влияют не только на покупательское поведение нового поколения, но и на их образ мышления с точки зрения социальной организации и экономической ценности.

Технологии играют ключевую роль в контексте экономики впечатлений, в частности, благодаря непрерывным инновациям, которые можно наблюдать на протяжении десятилетий.

Более десяти лет назад свой первый рывок вперед сделала мобильность, что позволило цифровым и физическим объектам объединяться и работать вместе. И именно благодаря этим типам инноваций, которые устраняют все больше и больше физических и цифровых барьеров и превращают работу по взаимодействию в товары, модели, основанные на опыте, становятся все более актуальными.

Теперь мир стоит перед третьим скачком вперед. 5G - это не просто эволюционное обновление предыдущего поколения мобильных телефонов, но и революционная технология, разработанная для устранения ограничений доступа, пропускной способности, производительности и задержки при подключении по всему миру. В области автомобилестроения транспортные средства используют информацию из «облака», тем самым повышая безопасность и эффективность дорожного движения. Так же развиваются в данном направлении заводы и умные города, которые смогут децентрализовать операции и поддерживать синергию, эффективность и контроль над каждым процессом и производством.

Такие технологии можно использовать и в здравоохранении, в таких случаях, как интернет- и роботизированная удаленная хирургия, имплантируемые устройства, дистанционный мониторинг, а также улучшить другие услуги по оказанию помощи, такие как дистанционный мониторинг уровня глюкозы в крови, ЭКГ и многое другое.

Миллениалы завоевали репутацию за свою склонность отдавать предпочтение опыту, а не продуктам. За последние несколько лет произошел тектонический сдвиг в расходах: в 4 раза больше средств было потрачено на впечатления, а не на физические товары.

«Впечатления» включает в себя следующую категорию услуг: членство в различных клубах, спортивные центры, парки, театр, мероприятия, музеи, азартные игры в казино, питание, проживание, авиаперелеты, пакетные туры, онлайн- 
подписки и зарубежные поездки жителей.

Новая экономика и распространение цифрового бизнеса с помощью мобильных приложений, веб-платформ и других средств привели к массовому восприятию наличия системы - системы взаимосвязанных цифровых данных и объектов, которые сотрудничают друг с другом и работают на нас.

Подъем такого сознания - это то, что определяет не только новые поколения, но и другие поколения, которые растут и живут в этом столетии (поколение X, Поколение Y и новое поколение Z).

Эти люди способны иметь целостное (или систематическое) представление о том, как все работает вместе и как система развивается. Это люди, выросшие в мире WWW, аббревиатура, которую можно интерпретировать как «Что угодно, когда угодно, где угодно», где можно получить все, что хочет человек, немедленно, где информация доступна каждому и где одним щелчком мыши или фотографией можно поговорить со всем миром. Вот что определило новый социальный порядок.

Помимо этого, появляется много новых форм социального поведения. FOMO (страх упустить) и FOBLO (страх остаться за бортом) становятся все более частыми в повседневной жизни всех поколений, и люди пытаются повысить ценность своих персональных качеств с помощью фотографий, подчеркивающих уникальные моменты и маленькие переживания.

Большая часть миллениалов сегодня находится в возрасте от 22 до 40 лет и сталкивается с миром, совершенно отличным от предыдущих поколений. Технический прогресс резко снизил цены на некоторые товары (и создал другие совершенно новые). Потребительские товары особенно технические - неуклонно снижаются в цене. Но предметы первой необходимости, такие как жилье и продукты питания, выросли, так как происходит рост заработной платы.

Между тем стоимость медицинского обслуживания также продолжает расти, что чревато катастрофой для миллениалов, чей высокий стресс и, как правило, меньшее количество поддержки приводят к более серьезным проблемам со здоровьем, чем у предыдущих поколений.

Многие родители поколений Y и Z, чтобы избежать риска в новом мире, пытаются убрать все, что может расстроить или напугать их детей, и вместо того, чтобы готовить ребенка к дороге, они очищают дорогу для ребенка.

Доступ ко всем видам информации, ко всем данным, к каждому человеку и наоборот напугал их, и во многих случаях они понятия не имеют, как с этим бороться. Эти поколения (Y и Z) страдают от гораздо более высоких показателей тревожности и депрессии, чем миллениалы в том же возрасте,- и более высоких показателей самоубийств.

Теперь, возвращаясь к деловым и экономическим аспектам, новые модели поведения создают благоприятную среду в решениях для некоторых впечатлений. Например, автоматизация рабочего пространства: роботы, искусственный интеллект, Интернет вещей и т.д.

Роботы (физические и цифровые), умные объекты и искусственный интеллект существуют уже много лет, и они уже выполняют многие производственные виды работ, но теперь новый скачок вперед знаменует собой изменение всего.

Согласно прогнозам, в 2030 году в мире может быть автоматизировано более 800 миллионов рабочих мест. Через 10 лет из-за роботов могут исчезнуть такие рабочие места, как сотрудники в банках, администраторы, водители, охранники и многие другие.

Полностью автоматизированные грузовики могут лишить работы половину дальнобойщиков в течение десятилетия. Технологии смогут заменить 60\%-70\% того, что делают врачи. Трейдеров смогут заменить машины. Половину маркетинговых заданий можно было бы заменить машинным интеллектом. Роботы могут уничтожить еще 6 миллионов рабочих мест в розничной торговле.

Все эти надвигающиеся перемены могут легко привести к утрате социальной структуры, что вызовет очень опасную напряженность в обществе. По этой причине существует общий страх перед этим надвигающимся вторжением автоматизированных технологий, но многие другие люди, особенно новые поколения, настроены более оптимистично.

Их мышление основано на идее экономики впечатлений. Если то, что мы продаем,- это опыт, рабочая сила должна быть отстранена от повторяющихся задач и рабочих мест и переведена на новые формы работы, более ценные в создании и определении ценности опыта. Новое поколение рассматривает автоматизацию технологий как необходимый инструмент для получения опыта, способный преобразовать наши 
рабочие места, а не заменить нас.

Самые сложные виды деятельности, которые необходимо автоматизировать,- это работа с знаниями: управление людьми, применение знаний для принятия решений или творческая работа.

Все чаще можно увидеть подростков, ведущих разговоры о «безопасности» и «инклюзивности» по телевизору (включая разговоры о равенстве, обвинениях в дискриминации и т.д.), и можно увидеть все больше молодых кандидатов, баллотирующихся на политические посты.

В Европе и Соединенных Штатах у молодых поколений растет экономическая неуверенность в их будущем, подчеркивая чувство «отсутствия контроля над своей жизнью», поэтому они ищут различные пути, которые бы смогли помочь им с этим.

Новые поколения формируются с таким взглядом, где рабочие места менее ориентированы на конкретные задачи; где бизнес стремится к участию потребителей, а не к продаже товаров; и где требуются новые формы экономической ценности, в то время как растет новый политический взгляд.

Растет популярность социалистов, многие из которых - миллениалы.

Социалисты считают, что неравенство вышло из-под контроля и что экономика подстроена в угоду корыстным интересам.

Равные, децентрализованные, безопасные, инклюзивные, систематические - вот слова будущего видения бизнеса для этой группы людей, где технологии играют ключевую роль в обеспечении правильной работы этой самоуправляемой машины.

В полностью автоматизированной рабочей среде представление о работе может измениться. Многие люди считают, что спросом будет 10или 12-часовая рабочая неделя, гарантированная заработная плата, гарантированное жилье, образование, здравоохранение и т.д.

Взять, к примеру, Uber, в 2030 году у него будет огромная глобальная сеть беспилотных автомобилей.

Таким образом, сегодня и, вероятно, в обозримом будущем нынешняя экономическая модель все еще адаптирует еще более современную модель «Экономики впечатлений (опыта)».

Не нужно думать и гадать о том, что будет в будущем,, но необходимо понимать те факты и идеи, которые сейчас активно транслируются в обществе, чтобы уметь адаптироваться к ним.

Технологии и автоматизация вызовут новые мысли и новые идеи о том, как с этим бороться. Новый подход будет продолжать создавать различные политические дискуссии и новые социальные трения.

Признаки растущей популярности экономики впечатлений здесь, без сомнения, присутствуют, и факторы (социальные, поколенческие, технологические и экономические) ускоряют это изменение экономической ценности.

Невозможно знать, каким будет будущее в деловом мире, но можно знать, в каком направлении оно движется.

\section{Библиографический список}

1. Экономика впечатлений: Как превратить покупку в захватывающее действие / Джеймс Х. Гилмор, Джозеф Б. Пайн II-М: Издательство «Альпина Паблишер», 2018. - 384 с.

2. Социокультурная экономика: как культура влияет на экономику, а экономика - на культуру. Курс лекций / А.А. Аузан, Е.Н. Никишина - М: Экономический факультет МгУ имени М. Ломоносова, 2021. - 200 с.

3. FOMO sapiens. Как избавиться от страха упущенных возможностей и начать принимать правильные решения / Патрик Макгиннис - М: Издательство «Альпина Диджитал», 2020. - 250 с.

4. Экономика культуры: учебник и практикум для академического бакалавриата / И. В. Чарная - М: Издательство «Юрайт», 2019. - 240 с.

5. Экономика ощущений и впечатлений в туризме и менеджменте / Н. А. Колодий - М: Издательство «Юрайт», 2018. - 326 c.

6. Mirco Pasqualini, Agencies \& Brands in the Experience Economy: Management Organization, 2019._ 208 c. 